\title{
WETLAND CHANGE DETECTION IN PROTECTED AND UNPROTECTED INDUS COASTAL AND INLAND DELTA
}

\author{
Muhammad Hasan Ali Baig ${ }^{1}$, Mubbashra Sultan ${ }^{1}$, Mobushir Riaz Khan ${ }^{1}$, Lifu Zhang ${ }^{2}$, Maria Kozlova ${ }^{3}$, Naeem Abbas Malik ${ }^{1}$, \\ Shudong Wang ${ }^{2}$ \\ ${ }^{1}$ Institute of Geo-Information and Earth Observation, Pir Mehr Ali Shah Arid Agriculture Univrsity Rawalpindi \\ (mhasanbaig@gmail.com, mubashrasial@gmail.com, Mobushir_riaz@yahoo.com,nnaeem.malik@uaar.edu.pk), ${ }^{2}$ Institute of \\ Remote Sensing and Digital Earth, Chinese Academy of Sciences (zhanglf@ radi.ac.cn, wangsd@ radi.ac.cn), ${ }^{3}$ State \\ Oceanographic Institute of Russia (clo@yandex.ru)
}

\section{CHGCS 2017, ISPRS}

KEY WORDS: Wetlands, Ramsar, Remote Sensing, Change Detection, classification, protected, degradation

\begin{abstract}
:
Worth of wetland sites lies in their ecological importance. They enhance ecosystem via provision of ecological services like improving water quality, groundwater infiltration, flood risk reduction and biodiversity regulation. Like other parts of the world Pakistan is also facing wetlands degradation. Ecological and economic significance of wetlands was recognized officially in 1971 as Pakistan became signatory of Ramsar wetland convention. Wetlands provide habitat to species of ecological and economic importance. Despite being recognized for international importance, Ramsar figures state that almost half of Pakistan's wetlands are at moderate or prominent level threat. Wetlands ecosystems are deteriorating at a rapid rate, if uncontrolled this trend may lead to substantial losses. Therefore, management of these resources demands regular monitoring. Present study is dedicated to assessing levels of change overtime in three distinct types of wetlands in Pakistan i.e. Indus delta a coastal wetland, Uchhali complex an inland wetland which are both protected sites while another site Nurri Lagoon which is not sheltered under any category of protected areas. Remotely sensed data has remarkable applications in change detection. Multitemporal Landsat images were used to map changes occurring from 2006 to 2016. Results reveal that wetland area has considerably decreased for all types. Both protected sites have experienced degradation though impact is comparatively lesser than unprotected Nurri lagoon. Significance of protection strategies cannot be denied, it is recommended that mere declaration of a site protected area is not sufficient. It is equally important to control non-point pollutants and ensuring the compliance of conservation strategy.
\end{abstract}

\section{INTRODUCTION}

Water has always been a key factor in sustaining life on planet earth. Despite having no colour and taste water has been the most cherishing resource since existence of life. Its royalty can be better understood by the fact that water is used as a key parameter in determining existence of life on other planets. The premier importance of water urges for wiseful use of this precious resource. Water is a critical resource its acute shortage can lead to drought while surplus supply can cause disaster like flooding. Therefore, reliable and dependable supply of water is necessary (Watkins 2006).

Wetlands come as natural solution to global water crisis. Wetlands, as the name describes are combination of terrestrial and aquatic conditions therefore, characterized as most complex ecosystems of the world. Their ecological importance is huge. As wetlands offer several ecosystem services such as enhancing water quality, groundwater recharge as well as flood control and biodiversity regulation. In addition to their ecological services wetlands offer multiple economic benefits. Wetlands produce commercially significant animals and plant species. Owing to the immense benefits of wetlands, the first treaty on conservation of wetlands was Ramsar convention 1971. The convention aimed at promoting wise use of this precious resource(Ramsar, Environment et al. 1997).

Pakistan, despite being in arid climatic region, is gifted with aquatic resources. Arabian sea presents apparently, an infinite supply of water but freshwater resources are very limited. As an agricultural economy, Pakistan is largely depending upon these resources for the wellbeing of people. Pakistan's wetland ecosystem runs with the Indus river and travels from mountainous peaks to the low lands and finally enters Arabian sea. Wetlands of Pakistan provide habitat to species of ecological and economic importance such as shrimp, lobster and fish and numerous migratory bird species get shelter at these wetlands every year. Anthropogenic activities at the sites as well as climatic variations are posing threat to wetlands. Regarding the economic and ecological importance of wetlands Pakistan became a signatory of Ramsar wetland convention in 
November 1976. 19 wetland sites of Pakistan are branded as sites of international importance (Khan 2006).

Several types of wetlands are found in Pakistan, mainly characterized as coastal wetlands, inland wetlands and manmade wetlands. As wetlands present unique environments, protection and preservation of these environments is highly appreciated. Ramsar statistics reveal that nearly half of the wetlands in Pakistan are under medium or prominent level threat. Prime value of Pakistan's wetlands lies in the fact that they cover a significant part of migratory bird's route. Hence wetlands degradation will not only hinder the national level economic and environmental benefits but also restrict migration of birds species and may lead to their extinction(Chaudhry 2010).

A classification type suitable for wetlands of Pakistan, categorizes wetlands as Indus Basin wetlands and non-Indus basin wetlands(Latif, Rasul et al. 2010). Present study is using three of the Ramsar wetland sites from Pakistan as case studies namely Indus delta wetland, Nurri Lagoon and Uchhali complex wetlands. All the three wetlands are categorized as Indus Basin wetlands. Indus delta wetland is a coastal wetland site and creates a complex ecosystem with swamps, streams and mangrove forests. The Uchhali wetlands complex is made of three independent wetlands namely Uchhali, Khabakki and Jahlar, located at salt range. The lakes rang from brackish to saline in nature. Uchhali wetlands complex and Indus delta wetlands are protected at various levels while the third site for this study, the Nurri Lagoon is not sheltered under any category of protected areas. Nurri lagoon is a natural wetland and is significant for its unique ecosystem. Nurri Lagoon presents a varying ecosystem with characteristics of coastal and inland wetlands as well as barren mudflats.

It is widely accepted that satellite images act as primary source for wetland change studies (Dahl 2004). High temporal resolution of satellite data sets allows change assessment over time. Landsat7 ETM+ images for year 2006 and Landsat 8 images of 2016 were obtained for all the wetland areas under consideration to assess changes taking place in these regions. Main objective of this study is to assess changes in landcover of these wetlands and identify the trends of change. The research also tries to identify factors causes degradation of wetlands. The study also evaluates the role of conservation strategies applied to the areas and difference between the conditions of protected wetlands and that of the unprotected.

\section{STUDY AREA}

Study area comprises of three of Ramsar wetland sites with varying ecological conditions.

\subsection{Uchhali wetlands complex}

The Uchhali wetlands complex of three wetlands namely Uchhali lake, Khabakki lake and Jahlar lake. They are treated as a complex because of their similar ecological conditions. Situated at $32^{\circ} 37^{\prime} \mathrm{N}$ and $072^{\circ} 00^{\prime} \mathrm{E}$ the lakes are protected under the categories of game reserve and wildlife sanctuary. The lakes rang from brackish to saline in nature.
Significance of Uchhali wetlands complex can be better understood by the fact that it is among the four hotspots identified by national wetlands program.

\subsection{Indus delta wetland}

The fifth largest wetland data of the world is located at $24^{\circ} 06^{\prime} \mathrm{N}$ and $067^{\circ} 42^{\prime} \mathrm{E}$. Indus river delta has a significant contribution to economic, environmental and ecological wellbeing of the region (Memon 2005). Indus delta is located where Indus river enters Arabian sea, and creates a complex ecosystem with swamps, streams and mangrove forests. Worth of Indus delta can be understood by the fact that it is globally the $5^{\text {th }}$ largest delta system and its mangrove forest is at number seven in the world.

\subsection{Nurri Lagoon}

Located at $24^{\circ} 30^{\prime} \mathrm{N}$ and $068^{\circ} 47^{\prime} \mathrm{E}$ Nurri lagoon has a unique ecology of inland and coastal wetland systems as well as the barren mudflats.

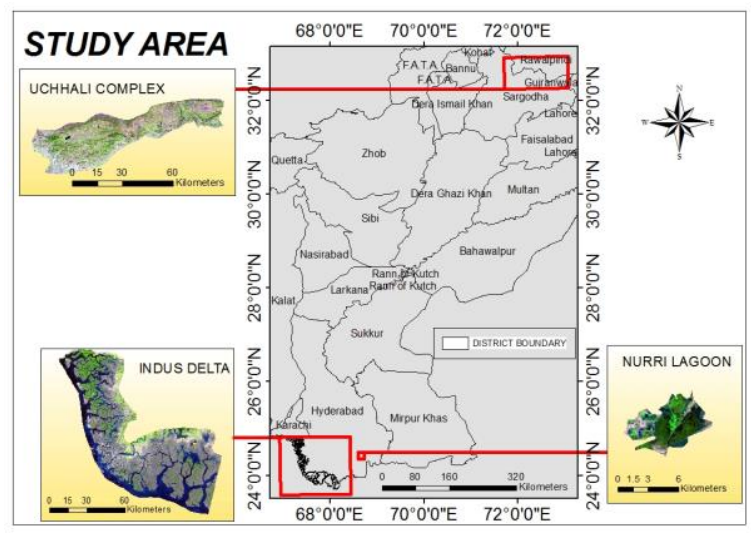

Figure 1. Study area map

\section{MATERIALS AND METHODS}

\subsection{Materials}

The datasets used in this study are Landsat7 ETM+ and Landsat8 images of October for years 2006 and 2016 respectively. Software involved in processing include ENVI 5.4, ERDAS IMAGINE 2015 and ArcMap 10.5.

\subsection{Methodology}

Change detection is a significant technique to identify the change with time. First step in land pattern classification was preprocessing through application of atmospheric corrections on Landsat7 ETM+ and Landsat8 images obtained from USGS. After this preprocessing, unsupervised classification through isodata clustering algorithm was performed as technique is widely appreciated for wetlands classification. For each wetland site both images were classified and spectral classes generated from unsupervised classification were assigned to suitable information classes. Finally, the change detection for before and after images i.e., 2006 and 2016 respectively was done in ERDAS IMAGINE using the image difference tool which provides per pixels 
change between given images of two different periods. The final maps displayed areas with notable change. The process was repeated for all the three wetland sites.

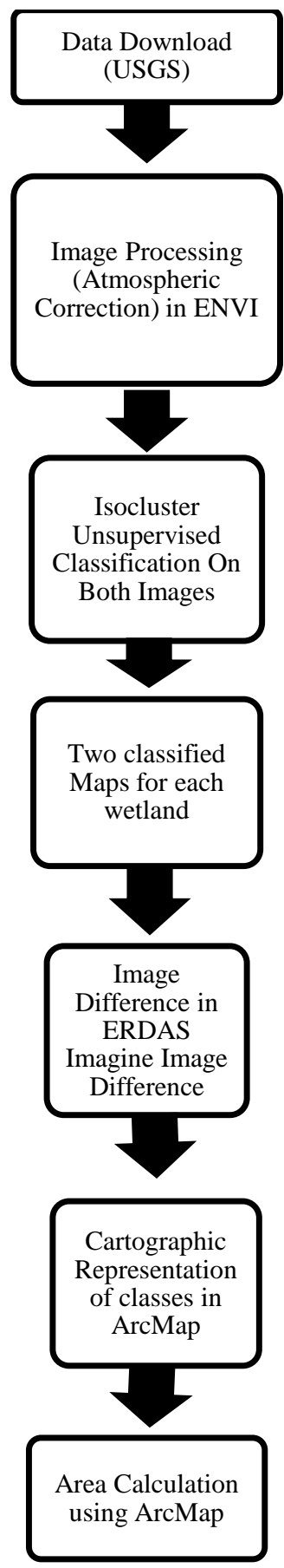

Figure 2. Methodology flow chart

\section{RESULTS AND DISCUSSION}

Wetland sites of this study have distinct ecological and environmental conditions the only factor constant between these sites is fact that urbanization, industrialization and intensive agricultural practices are taking place in vicinity of all these sites. Yet the considerable fact is their conservation status. Wetland degradation is matter of global concern as the rate of wetlands degradation was found considerably high during late twentieth and early twenty first century (Davidson 2014). This fact is highly disturbing as the role of Ramsar convention in wetlands conservation is apparently blurred. There is dire need to regularly inspect the conditions of wetlands and observe the trends and causes of change that will eventually help in better decision making. Present research is also a step towards this goal.

\subsection{Uchhali wetlands complex}

Uchhali complex became a part of Ramsar sites of international importance in 1996. The lakes of this complex occur independently but make a complex because of their ecological similarities. These lakes are harvested through the runoff from surrounding hills of salt range. Another unique characteristic of this complex is its height from sea level i.e., approximately $800 \mathrm{~km}$. Lakes are ranging from brackish to saline in nature. Salinity highly depends on rainfall and varies with change in rain pattern. Average annual rainfall ranges from $300 \mathrm{~mm}$ to $800 \mathrm{~mm}$ and size of lakes also increase with period of high rainfall and vice versa. As it provides habitat to rare species of duck Uchhali wetlands complex was given the status of wild life sanctuary and the Uchhali lake owns the status of game reserve. This can be regarded as an effort for the conservation of ecologically important species in that area but still efforts are needed to restore their environment and provide suitable conditions for survival(Hameed, Ashraf et al. 2010).

Lakes are not only affected from the amount of rainfall but also siltation which is reducing water depth and pollution from anthropogenic sources is also deteriorating them. To identify these significant parameters that have the potential to affect wetlands condition area surrounding this complex was also included in the change detection studies. Classification results for year 2006 produced four landcover classes namely water, vegetation, barren land and built up area. Vegetation was found to be prominent land cover and barren land was the second prominent class while built up area and water are at third at fourth rank respectively in landcover. Uchhali lake is largest among the

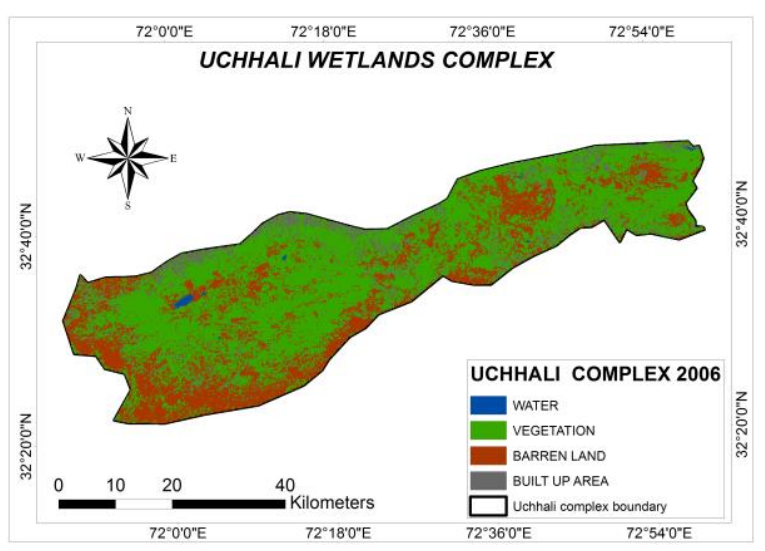

Figure 3. Classified map of Uchhali Complex 2006 
Classified map of 2016 showed notable change in vegetation and barren land where there is prominent decrease in vegetation while barren land and built up area have significantly increased, water is still covering minimum area.

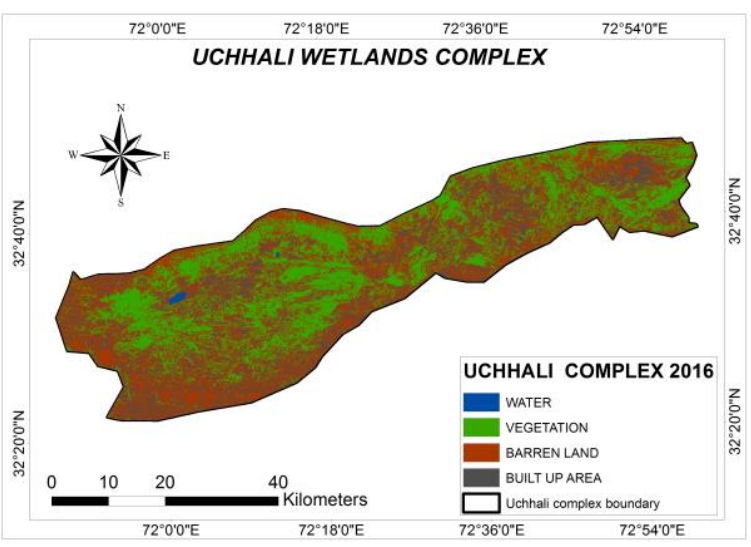

Figure 4. Classified map of Uchhali Complex 2016

Though agriculture is the main source of income for people in vicinity of the complex this decrease in vegetation cover reflects the effects of salinity which is prominent characteristic of study area. Though some grass species have adopted according to the environment and these resistant species can grow in the region but major agricultural crops of the area are wheat and vegetables. Production of wheat and maize is reducing in the area while conditions are suitable for some vegetables(Afzal, Younas et al. 1999).

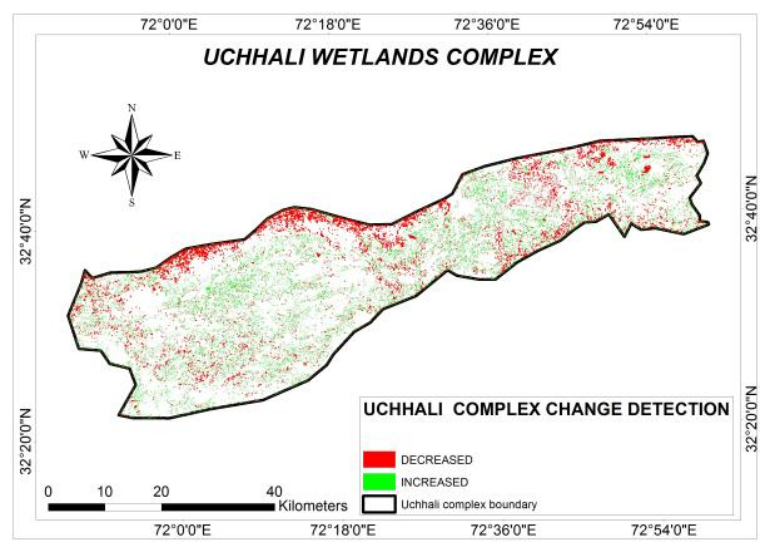

Figure 5. Map showing areas of notable change from 2006 to 2016

As urbanization is trending internationally and Pakistan is no exception hence within a brief time of ten years built up areas reached from $8 \%$ to $20 \%$ of the total area. Urbanization has an inherent conflict with natural environments therefore the impacts of salinity were combined with pollution from anthropogenic sources. Natural ecosystem is altered due to urbanization and intensive agriculture activity involving excessive use of pesticides and fertilizers.

\begin{tabular}{|c|l|c|c|c|c|}
\hline Year & $\begin{array}{l}\text { Land } \\
\text { cover }\end{array}$ & Water & Vegetation & $\begin{array}{l}\text { Barren } \\
\text { land }\end{array}$ & $\begin{array}{l}\text { Built } \\
\text { up area }\end{array}$ \\
\hline 2006 & $\begin{array}{l}\text { area } \\
\text { in ha }\end{array}$ & 601.42 & 141557 & 64426 & 18459 \\
\hline 2016 & $\begin{array}{l}\text { area } \\
\text { in ha }\end{array}$ & 444.33 & 80079 & 100178 & 44342 \\
\hline
\end{tabular}

Table 1: Area covered by landcover classes of Uchhali wetlands complex

All the three lakes of this complex come under the category of wildlife sanctuary and Uchhali lake is game reserve too, according to the international standards it is strictly prohibited to let the pollutants enter these protected zones. While though these lakes and hill forests are in the ownership of protection agencies. The agricultural lands in the region are owned by the people and there arises a conflict of resource management. Community involvement in wetland management process and raising awareness regarding significance of wetlands can help in resource management.

\subsection{Indus delta complex}

Indus delta is located where Indus river enters Arabian sea, and creates a complex ecosystem with swamps, streams and mangrove forests. Worth of Indus delta can be understood by the fact that it is globally the 5th largest delta system and its mangrove forest is at number seven in the world. Another factor that makes it exceptional is the fact that it receives maximum river energy.

The site gets international importance for providing habitat to world's rarest dolphin specie. Its mangrove forests are of great ecological and economic importance for the region One of the major threats to the wetland is construction of dams and diversion of water channel thus survival of species is threatened. An important specie under threat in this wetland in the rarest dolphin(Giosan 2014).

Construction of dams near delta regions cause irreversible effects and this is the case with Indus delta considerable area is eroded due to construction of dams. Mangrove forest of the region are also decreasing and besides their economic importance they act as buffers for flooding. With removal of mangroves threat to flood is increasing for Indus delta and delta region is contaminated with salts making the soils less productive hence discouraging local farmers(Coleman, Huh et al. 2008). Mangroves of Indus delta are declared as protected forest by the provincial forest department. Plans are on way to declare the site as heritage site and management plans for the wetland are also in process but they delay may lead to irreparable losses.

Classification of Indus delta for year 2006 produced five distinct classes including water, wetland, forest, barren land and built up area. Being the coastal delta, this wetland site had characteristics different from the other two sites involved in this study. Wetland area and water were top two 
landcovers, forest area also had significant appearance but barren land and built up area had a negligible contribution.

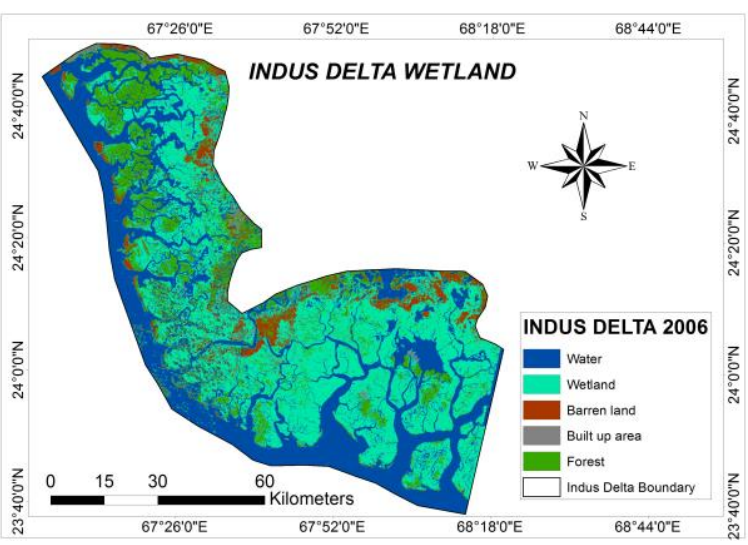

Figure 6: Landcover map of Indus Delta 2006

Classification results for 2016 showed decrease in water body and wetland area while forest and barren land very insignificant changes yet built up area has increased.

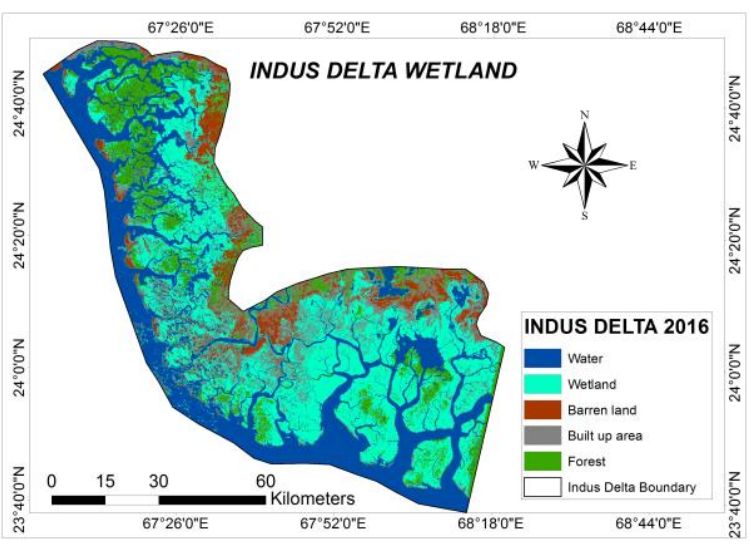

Figure 7: Landcover map of Indus Delta 2016

The most significant difference is seen in built-up area which is depicting global urbanization trend.

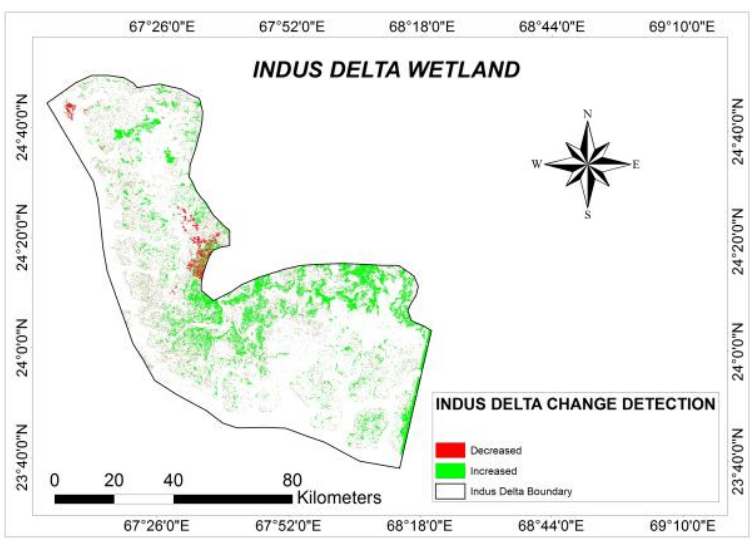

Figure 8: Map showing areas of notable change at Indus Delta Wetland
Wetland area and water both show a decrease though Arabian sea can provide interminable supply of water but supply is affected from Indus river due to damming and diversion of water channel to canals and agricultural fields. Now this will not only minimize the provision of river water but also reduces the nutrients supply to agricultural soils that are the key components for good yield. Therefore farmers are compelled to switch their sources of income to some reliable ways of living(Khan 2006).

\begin{tabular}{|c|c|c|c|c|c|c|}
\hline year & $\begin{array}{c}\text { Land } \\
\text { cover }\end{array}$ & Water & Wetland & $\begin{array}{c}\text { Barren } \\
\text { land }\end{array}$ & $\begin{array}{c}\text { Built } \\
\text { up }\end{array}$ & forest \\
\hline 2006 & Area & 282183 & 332786 & 43868 & 4177 & $\begin{array}{c}9741 \\
5\end{array}$ \\
\hline 2016 & Area & 255601 & 278807 & 53185 & $\begin{array}{c}8415 \\
0\end{array}$ & $\begin{array}{c}8868 \\
6\end{array}$ \\
\hline
\end{tabular}

Table 2: Area of landcover classes at Indus delta wetland

Coastal wetlands have more significance as compared to inland wetlands because of their capability to reduce the effects of natural disasters such as floods, drought and cyclones. Besides these local benefits their international significance is because of their ability to provide habitat to migratory birds and fish. Indus delta is also providing habitat to world's rarest dolphin which is already declared as endangered species hence it is necessary to make serious efforts rather than declaring as protected sites or taking years to devise plans for management.

Change detection results have shown lesser decrease in area covered by water from 2006 to 2016 but this does not offer a controlled condition but the fact is that though it is receiving significant amount of sea water the available freshwater is decreasing. Therefore, conservation strategies limited to site will not help in long term management. It is recommended to control diversions of Indus river tributaries and construction of water reservoirs without considering the demand at coastal region.

\subsection{Nurri lagoon wetland}

Province Sindh is rich in wetlands and ranges from large wetland areas to small lagoons. These coastal lagoons are of immense importance due to their unique ecology. Nurri lagoon has a combination of inland and coastal characteristics along with mudflats. It provides habitat to migratory birds and was declared Ramsar site of internal importance in 2001(Sultana 2015).

Landcover classification of Nurri lagoon resulted in four distinct classes including water, vegetation, built up area and barren land. In classified image of year 2006 largest are is covered by vegetation and built up area is almost negligible. While barren land and water are at third and fourth number respectively. 


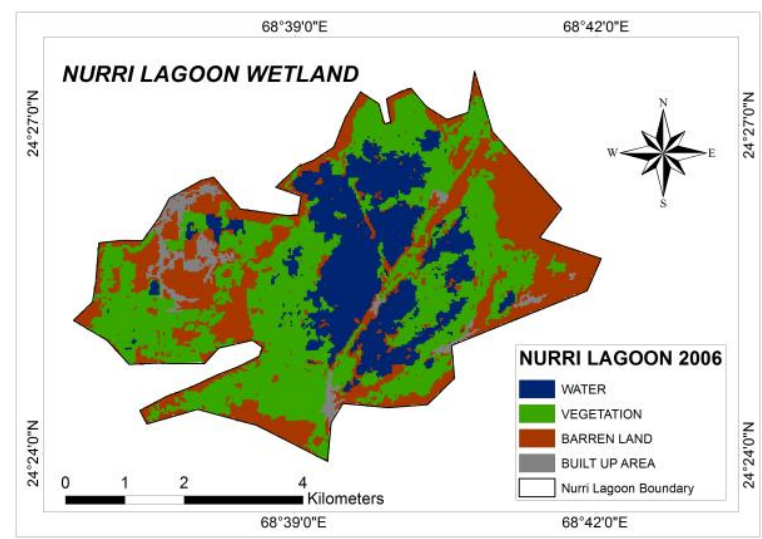

Figure 9: Landcover classification map of Nurri Lagoon 2006

There is significant amount of water seen during 2006 but there is considerable decrease in area of wetland water.

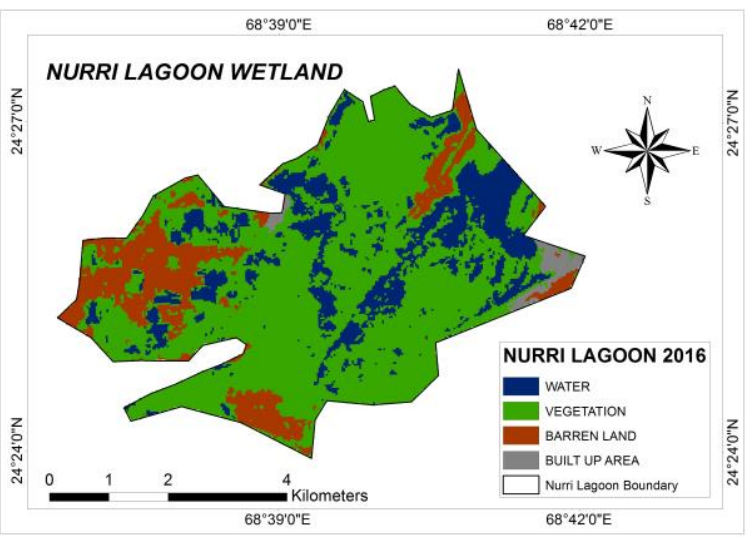

Figure 10: Landcover classification map of Nurri Lagoon 2016

Water has almost vanished from the main lagoon area found in 2006 while vegetation has increased during this period. Nurri lagoon is brackish in nature and because of ocean water intrusion its salinity is increasing.

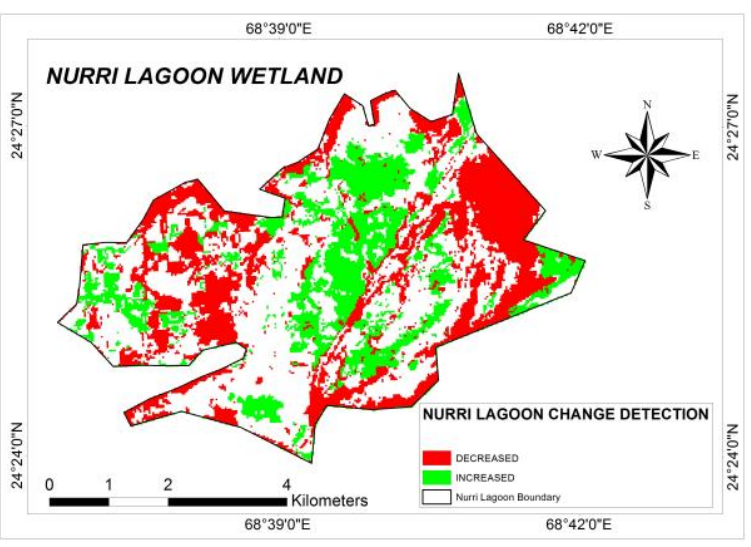

Figure 11: Map showing areas of notable increase and decrease in Nurri Lagoon
Change detection map shows areas with significant increase and decrease. Vegetation is increasing while barren land and water have decreased.

\begin{tabular}{|c|l|l|l|l|l|}
\hline $\begin{array}{l}\text { yea } \\
\text { r }\end{array}$ & $\begin{array}{l}\text { Landco } \\
\text { ver }\end{array}$ & $\begin{array}{l}\text { Wat } \\
\text { er }\end{array}$ & $\begin{array}{l}\text { Vegetat } \\
\text { ion }\end{array}$ & $\begin{array}{l}\text { barren } \\
\text { land }\end{array}$ & $\begin{array}{l}\text { built } \\
\text { up } \\
\text { area }\end{array}$ \\
\hline $\begin{array}{c}200 \\
6\end{array}$ & Area & 611 & 1297 & 882 & 108 \\
\hline $\begin{array}{c}201 \\
6\end{array}$ & Area & 548 & 1886 & 415 & 49 \\
\hline
\end{tabular}

Table 3: Areas in ha covered by landcover types in Nurri Lagoon

Nurri lagoon wetland is an internationally important site and is immense ecological and economic importance. Hence protection of this wetland site is highly recommended. Wetland site is surrounded by privately owned lands which are mainly villages. People of the are pose threat to wetlands as their main source of living is either fishing or agriculture. Increased agricultural activity pollutes wetlands through pollutants discharge in wetland area. Besides that, industrial pollution is more threatening as pollutants are directly discharged without any treatment. These situations it not controlled are likely to cause irreparable damage to this wetland site of international importance. Other two wetland sites in this study are protected in one way or the other yet they are not entirely safe from deterioration. While Nurri lagoon is not protected under any conservation strategy.

\section{CONCLUSION}

Wetlands of Pakistan gain international importance for covering the prime route of various internationally important migratory bird's species. 19 of Pakistan's wetlands are recognised as sites of international importance under Ramsar convention. Despite being accepted for their ecological and economic importance wetlands are degrading at a faster rate. Multitemporal change detection of three wetlands used as case studies for this research have shown considerable change within a period of ten years. Protection and conservation of wetlands is very important to sustain a healthy environment. Change detection is a prime technique for assessment of changes taking place in an area. Change detection results are helpful in recognising the impact of conservation strategies, if any. In this way, they can help in establishing long term management plans and scrutinising their results time to time. Remotely sensed data has made process more reliable and convenient. If change detection results are showing considerable losses as in our case studies, it is highly recommended to ensure conservation as well as restoration of sites. Though species are being protected at Uchhali and Indus delta wetlands being wildlife sanctuary and protected forest area. Considerable degradation demands for protection against pollutants from the neighbouring privately owned lands. Community 
involvement is necessary in conservation of shared resources.

\section{REFERENCES}

Afzal, S., et al. (1999). "Physical and chemical characterisation of the agricultural lands of the SoanSakesar Valley, Salt Range, Pakistan." Soil Research 37(6): 1035-1046.

Chaudhry, A. A. (2010). "Wetlands In Pakistan: What Is Happening To Them?" World Environment Day.

Coleman, J. M., et al. (2008). "Wetland loss in world deltas." Journal of Coastal Research 24(sp1): 1-14.

Dahl, T. E. (2004). Remote sensing as a tool for monitoring wetland habitat change. Monitoring Science and Technology Symposium: Unifying Knowledge for Sustainability in the Western Hemisphere, C. Aguirre-Bravo, PJ Pellicane, DP Burns and S. Draggan, Eds.

Davidson, N. C. (2014). "How much wetland has the world lost? Long-term and recent trends in global wetland area." Marine and Freshwater Research 65(10): 934-941.

Giosan, L. (2014). "Protect the world's deltas." Nature 516(7529): 31.

Hameed, M., et al. (2010). "Anatomical adaptations of Cynodon dactylon (L.) Pers., from the salt range Pakistan, to salinity stress. I. Root and stem anatomy." Pak J Bot 42(1): 279-289.

Khan, M. Z. (2006). Current status and biodiversity of Indus Dolphin Reserve and Indus Delta wetlands (Ramsar sites). Proc. 9th International River Symposium, Brisbane, Australia.

Latif, Z., et al. (2010). Assessment of ecological Process in Chashma wetland and its surroundings using isotopic techniques, Pakistan Institute of Nuclear Science and Technology.

Memon, A. A. (2005). Devastation of the Indus river delta. Impacts of Global Climate Change: 1-12.

Ramsar, B. d. 1. C. d., et al. (1997). Wetlands, biodiversity and the Ramsar convention: the role of the convention on wetlands in the conservation and wise use of biodiversity, Ramsar Convention Bureau Gland, Switzerland.

Sultana, S. (2015). "Linking Property Rights with Environmental Changes: The case of Nurerri and Jubho Lagoons, PakistanLinking Property Rights 